\title{
The Effect of Simulation versus Video-based training for Nursing Management of Normal Vaginal Delivery on Students' Practical Achievement and Satisfaction
}

\section{Safaa Ashry El sayed Eisaa1, Hoda Abd El azim Mohamed2، Ghada Abd El rahman Mahmoud3, Sahar Fahmy El Sayed4}

1. Department of Obstetrics and Gynecology, Faculty of Nursing, South valley university.

2. Professor of Women's Health and Obstetric Nursing , Faculty of Nursing Minia University.

3. Professor of Maternal and Newborn Health Nursing, Faculty of Nursing, Assuit university.

4. Assistant professor of Obstetrics and Gynecology, Faculty of nursing, South valley university

\begin{abstract}
Background: Nursing is a hands-on profession and students must demonstrate their ability to apply the concrete knowledge that they have learned in patient settings, students need to be taught, not only through lecture. The study aims to compare the effect of simulation versus video-based training, for nursing management of normal vaginal delivery among nursing students' practical achievement and satisfaction. Design: Quasi- experimental research design was used to conduct the study. Convenient sample of 87 nursing students, who were enrolled in the third year of baccalaureate nursing program. Tools: Three tools were used: 1- a self-administered questionnaire, 2- observational checklist was used to assess the students' practical achievement. It was mostly developed from a checklist supported by USAID 2008, and 3- Students' satisfaction scale. Result: the study revealed that the mean of the total practical achievement score of the simulation group was (55.9 \pm 4.89$)$, compared to $(45.14 \pm 4.95,43.97 \pm 5.9)$ in the vedio and control group .and in the satisfaction the mean in the simulation group was ( $24.24 \pm 0.69)$ compared to $(22.21 \pm 3.83$, $17.1 \pm 4.59$ ) in the vedio and control group ,that mean There was highly statistically significance between the simulation group and the vedio-based group and control group. Conclusion: simulation based training was more effective in improving the nursing students' practical achievement in nursing management of normal vaginal delivery, and also more satisfying to the nursing students than the video- based training experience. Recommendation: Integrating simulation training into current obstetric curriculums can aid nursing students in developing the clinical performance and skills.
\end{abstract}

Keywords: Effect, Simulation, Video-based training, Practical achievement, Satisfaction

\begin{abstract}
Introduction
Nursing education faces the challenges of drastic budget cuts and an ever increasing culturally diversestudent population, yet nursing education is also faced with the challenges offaculty shortages, limited clinical placement sites and experiences, nursing shortages thatdemand more nursing graduates, and higher expectations from employers, Nursing students often report lack of self-confidence and apprehension when they areexpected to meet performance criteria. ${ }^{(1)}$

The ultimate goal of undergraduateclinical nursing education is to create competent and safe entry-level practitioners. In order to do this, educators must provide students with the opportunity to learn in a safe environment. The use of simulation as an effective educational methodology is well-recognized and its use is now widespread in the training of health professionals worldwide, including nursing. ${ }^{(2)}$
\end{abstract}

Today, fewer nursing students have the opportunityto use their skills to provide comfort measuresand give supportive care for laboring women.Changes in the way women give birth can present adilemma for professors teaching in this area as wellas for the students whoare being prepared to carefor childbearing women ${ }^{(3)}$.

Nursing students today have limited opportunitiesto experience the normal labor.The opportunity for hands-on learning takes place in the care of postpartum patients and in the care of newborns in the nursery. ${ }^{(4)}$

The World Health Organization (WHO) defines normal birth as "spontaneous in onset, low-risk at the start of labor and remaining so throughout labor and delivery. The infant is born spontaneously in the vertex position between 37 and 42 completed weeks of pregnancy. After birth, mother and infant are in good condition. ${ }^{(5)}$

Simulation is potential tools that may help the nursing educators to prepare the future nurses to practice in a P a g e | 167 real environment. It is a teaching strategy that provides students with artificial representation of a complex real-life for enablingthem to learn in a safe environment; based on its degree of realism it ranges from low to high fidelity. Low fidelity simulation refers to that is used in teaching the physical assessment and psychomotor skills, while medium fidelity reflects more realism than that of low fidelity. Yet, high fidelity simulation refers to that which mimics the reality of a human patient in clinical environment. ${ }^{(6)}$

Simulation presents an opportunity for students to begin to learn and develop a nursing habitus. The opportunity to experience and act in a range of complex clinical situations through simulation enables healthcare students to learn the skills and practices of their discipline. Simulation also facilitates the development of an understanding of a clinical situation requiring specific responses and professional interactions while fostering the growth of professional identity. ${ }^{(7)}$

People learn effectively from multimedia instructions, and they are of particular importance for medical education. Furthermore, educational videos afford us "to capitalize on the ability of moving images to teach procedures requiring skilled techniques and specialized physical examination." Accordingly, video demonstrations of clinical skills have shown to improve learning of clinical skills and medical students appreciate the availability of such learning resources. ${ }^{(8)}$

Studies have shown the positive effects of audio visual aids in comparison with traditional methods on consciousness, satisfaction and stress reduction, Video is an important medium of learning through the use of videotapes ,video cassette records, made its appearance available at any time ,that help to enhance education ,these can be replayed and watched whenever necessary, video technology has made ahead way of education. . ${ }^{(9)}$

Safaa A., et al 


\section{Significance of the study}

The landscape of nursing education has changed dramatically in the past two decades resulting in a transformation of how nurse educators educate, Due to the severe nursing shortage along with a declining economy and increasing unemployment rate, schools of nursing are instituting creative ways to increase student proficiency. ${ }^{\mathbf{( 1 )}}$

The World Health Organization (WHO, 2016) has provided standards for nursing education and recommends the use of simulation. Simulation is a necessary technique in nursing education because it helps students to apply clinical skills while keeping patients safe and offers students the opportunity to practice clinical skills until they become proficient in performing certain tasks, Limited research is available on effectiveness and outcomes when using simulated scenarios in nursing education. With emphasis on safe and accurate care to patients, using simulators allows for practice in a non-threatening environment. ${ }^{(\mathbf{1 0})}$

The National League for Nursing (NLN), endorsed simulation use to prepare students for complex clinical and critical thinking skills. Despite an increasing number of nursing education programs that use simulation, there is a lack of researchinvestigating its effect on nursing students' learning. (9)

\section{Aim of the Study}

This study aimed to compare the effect of simulation versus video-based training, for nursing management of normal vaginal delivery among nursing students' practical achievement and satisfaction.

\section{Research Hypotheses:-}

- Nursing students who will receive simulation training for nursing management for normal vaginal delivery will have a higher score level of (a) practical achievement and (b) satisfaction than nursing students who will receive a video-based training.

\section{Subjects and Methods \\ Research Design:} of this study.

Quasi experimental design was used to fulfill the aim

\section{Setting}

Obstetrics and Gynecological Nursing Labs at the Faculty of Nursing- south valley University, Qena. , and Qena general hospital at which the clinical evaluation was conducted.

\section{Sample:-}

A convenient sample of 87 nursing students Participated in the study, who were enrolled in the third year of baccalaureatenursing program; when they assigned to the obstetric and gynecological nursing course during the $2^{\text {nd }}$ semester of the academic year 2017-2018 they were divided randomly in to three groups (simulation video and control group ) each group had 29 student.

\section{Inclusion Criteria:-}

Students who didn't receive labor and delivery simulation training, video based training, or clinical experience in labor and delivery nursing management before the enrollment, and who agreed to participate in the study.

\section{Data Collection Tools:}

Tools for the study was developed by the researcher after extensive review of literature and similar studies conducted elsewhere. After developed tools by researcher for data collection. Tools will be revised by panels of five expertises in obstetrical and gynecological nursing staffs. The data collection tools consisted of three tools:

\section{Tools of the Study:}

The first tool (self-administered Questionnaire):- included the socio-demographic data of the students including name, age, and residence.

\section{The second tool: (Observational checklist)}

An observational checklist was used to assess the students' practical achievement in nursing management of normal labor. Tool was mostly developed from a checklist which supported by USAID 2008 and from the literature. ${ }^{(11)}$.

\section{Scoring System:}

It consisted of (20) items: (5) items focused on preparation for spontaneous vaginal delivery (3) items focused on supportive care, (3) items focused on maternal-fetal monitoring, (9) items focused on performing basic nursing actions The students answers related to checklist was scored and calculated.Each item had (3) scores if was competently performed; (2) scores if was incompletely performed, and (1) score if the task wasn't performed. Total score ranged from 20 to 60 , the higher score indicated the better achievement. These scores were converted into a percent score (poor practical achievement scored $<50 \%$, average practical achievement $50 \%-<75 \%$ and good practical achievement scored $75 \%$ or more).

\section{The third tool: - (Students' satisfaction scale)}

Safaa Ashry Students' satisfaction with the training experience was assessed using a scale developed by the National League for nursing (2005). ${ }^{(12)}$

\section{Scoring System for student satisfaction}

It consisted of five items, to measure the students' satisfaction with the two assigned training experiences either simulation or video based training and also the satisfaction of the control group (traditional lecture). Each item had scores using a 5 point Likert scale. strongly agree had score 5 , agree had score 4, undecided had score 3, disagree had score 2, while Strongly disagree had score 1 . Total score ranged from 5 to 25 , the higher score indicated the higher satisfaction. The students answers related to the satisfaction scalewere scored and calculated,these scores were converted into a percent score (poor satisfaction scored $<50 \%$,average satisfaction $50 \%-<75 \%$ and satisfaction scored $75 \%$ or more).

\section{Tools Validity and reliability}

Tools were submitted to a panel of 5 experts in the field of Women Health \& Obstetric Nursing in Minia and Assiut university and confirmed it's validity, modifications on the tools were done according to the panel judgment in relation to appropriateness of the content and accuracy of items. Tools of the study were tested for their reliability using Cronbach's alpha test 


\section{Pilot study:}

A pilot study was conducted on $10 \%$ of the Nursing students, was equal to 9 students, to ascertain the clarity and comprehensiveness of the tools as well as to estimate the appropriate time required for procedure and to test study process. Results of the pilot study illustratedthat no any refinements and modifications were needed so the subjects were included to the actual sample.

\section{Ethical Consideration:}

A written initial approval was obtained from the research ethical Committee of the Faculty of Nursing, Minia University,Approval to conduct the study was obtained from the dean of the faculty of Nursing, south valley university.And oral consent was obtained from students that were willing to participate in the study, after explaining the nature and purpose of the study.Participants were informed that their participation in the study was completely voluntary andacceptance of participants was obtained.

\section{Data collection procedure:}

- The researcher Prepared (the Noelle birth simulator) and the required facilities and, equipment needed for a spontaneous vaginal delivery, and the students were randomly divided to three groups, the simulation based training group, video-based training group, and the control group each group had 29 students...

- The simulation group received the simulated delivery room classes at the obstetric and gynecological nursing labs before attending the clinical training at the real labor and delivery room (Hospital). Simulated delivery room classes were provided over a six weeks period in small groups. Each group spent 30-45 minutes to perform the task, the simulation training was conducted in the first three days of the week after the end of the lectures and the sections of each day .and the students were divided in to smaller groups each group consisted of four students ,two students assumed the role of managing the labor process while the other two assumed the role of nurse that performing the newborn care , and then they changed the roles, so that all students received the simulation training.

- The simulation training sessions repeated more than once to make sure that all students not needed more training.
- The video-based training group received the training on management of normal vaginal delivery at the obstetrics and gynecological nursing labs by using video recording with the data show projector. The training was gone on 30 minute, without attending the simulation classes, the students in this group were divided in to smaller groups also.

- The Control group also received the traditional lecture on management of Normal vaginal delivery as what was used to be done, it had been considered as apart from theoretical lectures ,the control group wasn't received either the simulation training or the vedio based training in this phase of work.

- The training of the students and the clinical evaluation were performed from March through May2018.

- All the three groups were evaluated after finishing the training by two weeks usingfull observational checklist during management of normal vaginal delivery in the department of obstetrics and gynecology inQena general hospital, and students satisfaction was evaluated using the satisfaction scale and the results of the threegroups of simulation and video -based training, and the control group were compared to determine difference between the groups.

- After finishing the training and the clinical evaluation of the three groups, the rest of the groups also received the simulation training for the vedio based and control group, and also they received vedio training for the simulation and the control group.

\section{Statistical analysis}

The data were tested for normality using the Anderson-Darling test and for 'homogeneity variances prior to further statistical analysis. Categorical variables were described by number and percent ( $\mathrm{N}, \%)$, where continuous variables described by mean and standard deviation (Mean, SD). Chi-square test and fisher exact test used to compare between categorical variables where compare between continuous variables by t-test land ANOVA TEST. A two-tailed $p<0.05$ was considered statistically significant. Person Correlation was used to appear the association between scores.All analyses were performed with the IBM SPSS 20.0 software .

\section{Results: The results of this study are presented as the following headings:}

Part I: Socio-demographic characteristics of the studied sample (Table 1)

Part II: Practical achievement scores of the student groups (Table 2)

Part III: Satisfaction scale scores of the student groups (Table 3).

Part IV: Multiple Comparisons between student groups according to Practical achievement scores and Satisfaction scale scores (Tables 4).

Part V: Correlation co efficient between Practical achievement scores and Satisfaction scores (Tables 5).

Part VI: Relationship between mean of practical achievement scores of the students with their Socio demographic data (Tables 6).

Part VII: Relationship between mean of satisfaction scores of the students with their Socio demographic data (Tables 7) 
I - Socio demographic characteristics.

Table (1) Distribution of the students regarding to their sociodemographic characteristics

\begin{tabular}{|c|c|c|c|c|c|c|c|}
\hline \multirow[b]{2}{*}{ Variable } & \multicolumn{2}{|c|}{ Simulation } & \multicolumn{2}{|c|}{ Video } & \multicolumn{2}{|c|}{ Control } & \multirow[b]{2}{*}{ P. value } \\
\hline & $\begin{array}{c}\text { No } \\
(n=29)\end{array}$ & $\%$ & $\begin{array}{c}\text { No } \\
(n=29)\end{array}$ & $\%$ & $\begin{array}{c}\text { No } \\
(n=29)\end{array}$ & $\%$ & \\
\hline \multicolumn{8}{|l|}{ Sex } \\
\hline Male & 0 & 0.0 & 1 & 3.4 & 22 & 75.9 & \multirow{2}{*}{$0.001 * *$} \\
\hline Female & 29 & 100.0 & 28 & 96.6 & 7 & 24.1 & \\
\hline \multicolumn{8}{|l|}{ Age } \\
\hline$<20$ year & 1 & 3.4 & 1 & 3.4 & 1 & 3.4 & \multirow{3}{*}{0.731} \\
\hline$-20-22$ years & 28 & 96.6 & 28 & 96.6 & 27 & 93.1 & \\
\hline$->22$ years & $\cdot$ & 0.0 & $\mathbf{0}$ & 0.0 & 1 & 3.4 & \\
\hline \multicolumn{8}{|l|}{ Residence } \\
\hline Urban & 15 & 51.7 & 5 & 17.2 & 1 & 3.4 & \multirow{2}{*}{$<0.001 * *$} \\
\hline Rural & 14 & 48.3 & 24 & 82.8 & 28 & 96.6 & \\
\hline Mean \pm SD(rang) & \multicolumn{2}{|c|}{$21.38 \pm 0.78(19-22)$} & $21.28 \pm$ & 9-22) & \multicolumn{2}{|c|}{$21.28 \pm 0.7(19-23)$} & 0.830 \\
\hline
\end{tabular}

\section{- Chi-square test, ** Significant difference at p. value $<0.01$ Anova test}

Data in Table (1) Illustrates distribution of the studied students regarding to their socio demographic characteristic, regarding to age present study was noticed that the majority of the students their age ranged between 20-22 years, regarding to their residence the majority of the students were living in rural areas, and regarding to their sex, it was observed that two thirds of the students were females while one third of the students were males.

\section{II- Practical achievement scores of the students.}

Table (2) Comparison between studnt groups according to practical achievement.

\begin{tabular}{|c|c|c|c|c|c|c|c|}
\hline Variables & $\begin{array}{l}\text { No.of } \\
\text { items }\end{array}$ & Score & Simulation & Video & Control & $\mathbf{F}$ & P. value \\
\hline $\begin{array}{llll}\begin{array}{l}\text { preparation for } \\
\text { delivery }\end{array} & \text { spontaneous vaginal } \\
\end{array}$ & 5 & 15 & $14.69 \pm 1.67$ & $14.14 \pm 1.64$ & $13.69 \pm 1.89$ & 2.407 & $<0.001 * *$ \\
\hline maternal-fetal monitoring & 3 & 9 & $8.41 \pm 0.95$ & $5.93 \pm 1.69$ & $5.24 \pm 1.94$ & 32.262 & $<0.001 * *$ \\
\hline Performing basic nursing actions. & 9 & 27 & $25.21 \pm 1.92$ & $19.45 \pm 2.78$ & $20.28 \pm 3.29$ & 37.859 & $<0.001^{* *}$ \\
\hline Total scoring & 20 & 60 & $55.9 \pm 4.89$ & $45.14 \pm 4.95$ & $43.97 \pm 5.9$ & 45.191 & $<0.001 * *$ \\
\hline
\end{tabular}

\section{- Anova - test ** Significant difference at p. value $<0.01$}

Table (2): Reveals Comparison between student groups according to practical achievement, shows that there was highly statistically significant difference between student groups regarding to total mean of scores of practical achievement, with mean of the practical achievement of the students in the simulation group $(55.9 \pm \mathbf{4 . 8 9})$ compared to total mean scores of $(\mathbf{4 5 . 1 4} \pm \mathbf{4 . 9 5}, \mathbf{4 3 . 9 7} \pm \mathbf{5 . 9})$ in the vedio and control groups, $\mathrm{p}$ value $<0.001 * *$

Table (3) Comparison between student groups according to satisfaction scale scores of the students.

\begin{tabular}{|c|c|c|c|c|}
\hline Variable & Group & Mean \pm SD & $\mathbf{F}$ & P. value \\
\hline \multirow{3}{*}{$\begin{array}{l}\text { The teaching methods used in this clinical training were helpful and } \\
\text { effective }\end{array}$} & simulation & $4.93 \pm 0.26$ & \multirow{3}{*}{18.545} & \multirow{3}{*}{$<0.001 * *$} \\
\hline & Video & $4.52 \pm 0.95$ & & \\
\hline & Control & $3.66 \pm 1.01$ & & \\
\hline \multirow{3}{*}{$\begin{array}{l}\text { the clinical training provided me with a variety of learning Materials } \\
\text { and activities }\end{array}$} & simulation & $4.97 \pm 0.19$ & \multirow{3}{*}{26.219} & \multirow{3}{*}{$<0.001 * *$} \\
\hline & Video & $4.41 \pm 0.87$ & & \\
\hline & Control & $3.55 \pm 0.95$ & & \\
\hline \multirow{3}{*}{ I enjoyed how my instructor taught the clinical training } & simulation & $4.86 \pm 0.35$ & \multirow{3}{*}{24.684} & \multirow{3}{*}{$<0.001 * *$} \\
\hline & Video & $4.34 \pm 0.86$ & & \\
\hline & Control & $3.21 \pm 1.29$ & & \\
\hline \multirow{3}{*}{$\begin{array}{l}\text { The teaching material used in the clinical training was motivating and } \\
\text { helped me to learn }\end{array}$} & simulation & $4.62 \pm 0.49$ & \multirow{3}{*}{14.824} & \multirow{3}{*}{$<0.001 * *$} \\
\hline & Video & $4.41 \pm 0.95$ & & \\
\hline & Control & $3.38 \pm 1.21$ & & \\
\hline \multirow{3}{*}{$\begin{array}{l}\text { The way my instructor taught the clinical training was suitable to the } \\
\text { way I learn }\end{array}$} & simulation & $4.86 \pm 0.35$ & \multirow{3}{*}{22.185} & \multirow{3}{*}{$<0.001 * *$} \\
\hline & Video & $4.52 \pm 0.83$ & & \\
\hline & Control & $3.31 \pm 1.34$ & & \\
\hline \multirow{3}{*}{ Total satisfaction } & simulation & $24.24 \pm 0.69$ & \multirow{3}{*}{32.526} & \multirow{3}{*}{$<0.001 * *$} \\
\hline & Video & $22.21 \pm 3.83$ & & \\
\hline & Control & $17.1 \pm 4.59$ & & \\
\hline
\end{tabular}

\section{- Anova - test ** Significant difference at $\mathbf{p}$. value $<0.01$}

Table (3): Illustrates comparison between student groups according to Satisfaction scores, and also shows that the mean of the total satisfaction of the students in the simulation group was $(24.24 \pm 0.69)$,compared to $(22.21 \pm 3.83)$ and (17.1 \pm 4.59$)$ in the vedio and the control group , that mean There was highly statistically significant difference between the groups regarding to total mean of the satisfaction scoresp value $<\mathbf{0 . 0 0 1}$ **. 
Minia Scientific Nursing Journal (Print) (ISSN 2537-012X) Vol. (6) No. (1) December 2019

Table (4) Multiple comparison between student groups according to mean of practical achievement scores and mean of satisfaction scores

\begin{tabular}{|c|c|c|c|c|c|c|}
\hline Variable & Group & Mean \pm SD & P. value & P1 & P2 & P3 \\
\hline \multirow{2}{*}{ practical achievement } & Simulation & $55.9 \pm 4.89$ & \multirow{2}{*}{$<0.001 * *$} & \multirow{2}{*}{$<0.001 * *$} & \multirow{2}{*}{$<0.001 * *$} & \multirow{2}{*}{0.399} \\
\hline & Control & $43.97 \pm 5.9$ & & & & \\
\hline \multirow[t]{2}{*}{ Satisfaction } & Video & $22.21 \pm 3.83$ & \multirow[t]{2}{*}{$<0.001 * *$} & \multirow[t]{2}{*}{$0.028^{*}$} & \multirow[t]{2}{*}{$<0.001 * *$} & \multirow[t]{2}{*}{$<0.001 * *$} \\
\hline & Control & $17.1 \pm 4.59$ & & & & \\
\hline
\end{tabular}

- Anova - test ** Significant difference at $\mathbf{p}$. value $<0.01$

P. value :- comparison between all group

P1:- comparison between simulation\& Video

P2:- comparison between simulation\& Control

P3:- comparison between Video \& Control

As shown in table (4) : It illustrated Multiple comparison between student groupsaccording to mean of practical achievement score and satisfaction scores, it showed that the mean of the total practical achievement score of the simulation group (55.9 \pm 4.89$)$, compared to $(45.14 \pm 4.95,43.97 \pm 5.9)$ in the vedio and control group and in the satisfaction the mean in the simulation group was ( $24.24 \pm 0.69)$ compared to $(22.21 \pm 3.83,17.1 \pm 4.59)$ in the vedio and control group ,that mean There was highly statistically significance between the simulation group and the other two groups (vedio training, control ).

Table ( 5 )Correlation co efficient between mean of practical achievement scores and mean of satisfaction scores .

\begin{tabular}{|l|l|l|l|l|l|}
\hline Variable & Score & Range & Mean \pm SD & R & P \\
\hline Satisfaction & 25 & $5-25$ & $21.18 \pm 4.57$ & \multirow{2}{*}{0.318} & \multirow{2}{*}{$0.003^{* *}$} \\
\hline practical achievement & 60 & $33-60$ & $48.33 \pm 7.5$ & 0.0 \\
\hline
\end{tabular}

** Statistically Significant correlation at $\mathbf{p}$. value $<0.01$

Data in Table (5): Illustrates that the correlation coefficient between mean of practical achievement and mean ofsatisfaction, it showed that there was positive correlation between the practical achievement score and the satisfaction, and also better practical achievement, the more satisfaction of the students. And there was statistically significant correlation $\mathbf{p}$ value $<\mathbf{0 . 0 0 3 * *}$.

Table (6) Relationship between mean of practical achievement scores of the students with their sociodemographic variables

\begin{tabular}{|l|c|c|c|}
\hline \multirow{2}{*}{} & \multicolumn{3}{|c|}{ practical achievement } \\
\cline { 2 - 4 } & Simulation & Video & Control \\
\cline { 2 - 4 } & Mean \pm SD & Mean \pm SD & Mean \pm SD \\
\hline Age & & & \\
\hline$<20$ year & $48 \pm 0$ & $46 \pm 0$ & $49 \pm 0$ \\
\hline$-20-22$ years & $56.18 \pm 4.73$ & $45.11 \pm 5.04$ & $43.41 \pm 5.69$ \\
\hline$->22$ years & - & - & $54.0 \pm 0$ \\
\hline P. value & $\mathbf{0 . 1 0 1}$ & $\mathbf{0 . 8 6 3}$ & $\mathbf{0 . 1 4 5}$ \\
\hline Residence & & & \\
\hline Urban & $56.07 \pm 4.33$ & $45.25 \pm 3.59$ & $47 \pm 0$ \\
\hline Rural & $55.71 \pm 5.58$ & $45.12 \pm 5.2$ & $43.86 \pm 5.98$ \\
\hline P.value & $\mathbf{0 . 8 5 5}$ & $\mathbf{0 . 9 6 2}$ & $\mathbf{0 . 6 1}$ \\
\hline
\end{tabular}

Independent T- test - Anova - test

Data in Table (6): Illustrates that the relationship between socio-demographic characteristic of the students and the mean of practical achievement scores and also showed that there was no statistically significance between practical achievements of the studentsand their age and residence.

Table (7)Relationship between mean of satisfaction scores of the studentswith their socio demographic variables

\begin{tabular}{|l|c|c|c|}
\hline \multirow{2}{*}{ Variable } & \multicolumn{3}{|c|}{ satisfaction score } \\
\cline { 2 - 4 } & Simulation & Video & Control \\
\cline { 2 - 4 } & Mean \pm SD & Mean \pm SD & Mean \pm SD \\
\hline$<20$ year & & & \\
\hline$-20-22$ years & $24.21 \pm 0.69$ & $22.18 \pm 3.9$ & $17.33 \pm 4.6$ \\
\hline$->22$ years & $0 \pm 0$ & $0 \pm 0$ & $11 \pm 0$ \\
\hline P.value & 0.270 & 0.837 & 0.413 \\
\hline Residence & & & \\
\hline Urban & $24.33 \pm 0.72$ & $22.5 \pm 4.36$ & $19 \pm 0$ \\
\hline Rural & $24.14 \pm 0.66$ & $22.16 \pm 3.84$ & $17.04 \pm 4.65$ \\
\hline P.value & 0.466 & 0.981 & 0.682 \\
\hline
\end{tabular}

Independent T- test - Anova - test .

Table (7) :): Illustrates that the relationship between socio-demographic characteristic and the mean of satisfaction scores of the students and also show that there was no statistically significance between satisfaction scores of the students and their age and residence. 


\section{Discussion}

The World Health Organization (WHO) has provided standards for nursing education and recommended the use of innovative teaching strategy for simulation in nursing education ${ }^{(10)}$. Skills learning experiences such as simulation teaching help to prepare students for the realities of the health care field. In Midwifery education, simulation is an educational strategy that has the potential to engage learners in realistic learning environments where they can practice skills and care for patients without being overly concerned about harming the patients. ${ }^{(13)}$

The study findings revealed that students of the simulation group had achieved higher practical achievement scores than those of the vedio based training group and control group!and the total mean score of the practical achievement of the students was significantly high in the simulation group ( $55.9 \pm 4.89)$ compared to total mean scores of $(45.14 \pm 4.95$, $43.97 \pm 5.9)$ in the vedio and control groups with $p$ value $<0.001^{* *}$. Accordingly the study hypothesis was accepted, "Nursing students who will receive simulation training for management of normal vaginal delivery will have a higher level of (a) practical achievement than nursing students who receive a video-based training."

The study findings were consistent with prior research studies that had evaluated the effect of simulation based education on nursing students' practical achievements and indicated a higher clinical performance post simulation.

That came in accordance with a study performed in Mansura university, about (Effectiveness of simulated delivery room classes on practical achievement and satisfaction of maternity nursing students) by (Marzouk ,2015) who concluded that"Simulated delivery room classes were an effective trainingapproach; they were equipped the students with practicesthat resulted in a significantly higher practical achievements compared to the conventional training." (6)

As in a study performed by (Ardic,et al 2016 ) in in the United States of America at the College of Nursing at The Ohio State University ,(Undergraduate Nursing Students' Perceptions of Obstetric Skills Following High-Fidelity Simulation Experience), who reported that" Nearly the entirety of the students in their search reported that they found the simulation model significant for gaining obstetric skills, and their communication skills with the patients and team improved. The debriefing sessions were identified as important to the observance of the effectiveness of the initiatives and that the simulation model reflected the real clinical setting in application". (14)

That came in accordance with (Young et al.'s ,2012 ) in a study about (Effects of Simulation-based Education onCommunication Skill and Clinical Competence in Maternity NursingPracticum) The authors concluded that "the performance score of the simulation based education group was increased by 0.63 points while the score of the control group increased by 0.15 points, indicating a significant difference between the both groups." (15)

Parallel with this finding, (Daniels et al, 2010) pointed out in a study about (Prospective Randomized Trial of Simulation versus Didactic Teaching for Obstetrical Emergencies. Society for Simulation in Healthcare. ), that" the performance testing showed a statistically significant higher scores for the simulation group towards both shoulder dystocia (Simulation $=11.75$, Didactic $=6.88)$ and eclampsia management $\left(\right.$ Simulation $=13.25$, Didactic 11, ., 38)". ${ }^{(16)}$.
The findings of the study alsoare in line with the findings in a systematic review performed by (Cooper. $s$ et al 2010) about (Simulation-based learning in nursing education systematic review ) whose results concluded that "Medium and/or high fidelity simulation using manikins was an effective teaching and learning method when best practice guidelines were adhered to. Simulation may have some advantage over other teaching methods, depending on the context, topic and method."(17)

While The findings of the present study are in contrast with a study performed by (Asadollahi and colleagues ,2016) about (Comparing the Effect of Simulation and Video-based Education on Mothers Self-Efficacy in Bathing Preterm Infants ), in Iran, who concluded that "simulation and educational video have the same effect on improving mothers' self-efficacy for bathing preterm infants., and the results showed that= both methods positively affected learning among students but there was no significant difference between the two methods". ${ }^{(18)}$

That came also in accordance with (Kim, and colleagues 2012) who reported in a study about (Effects of Simulation-based Education on Communication Skill and Clinical Competence in Maternity Nursing Practicum) that "The simulation-based education in maternity nursing practicum was effective in promoting communication skill and clinical competence. With application of diverse clinical situation scenarios, and that it was recommended to develop and apply simulation-based education using a high-fidelity simulator in the area of maternity nursing". (19)

That came also in accordance with (Gefferie, S. R., Scholten, A. W., Wijlens, K. A., ,2018)) in a study about ( An empirical model for educational simulation of cervical dilation in first-stage of labor ) who concluded that " An original empirical model for educational simulation of oxytocin concentration, uterine contractions, and cervical dilation in first-stage labor is presented. Simulation results for cervical dilation matched target data for a normal patient. The model formed a basis for taking into account more independent variables and patient profiles and could thereby considerably expand the range of training scenarios that can be simulated."(20)

The higher practical achievement scores reported by the simulation group in the present study may be explained by the fact that the students trained by doing, and applying the procedures by themselves on areal-like patient (simulated ), not just seeing, and they had the opportunity of repeating the training, andthe presence of a realistic patient environment compared with the traditional training.

Also the students had the opportunity to perform the clinical procedure without fearing of making harm to the patient and that helped them to perform with more confidence and this is very necessary to prepare them to be proficient in the clinical practice, The results provided evidence to support the integration of simulation as an effective teaching strategy that helped to improve students' knowledge and confidence in applying clinical skills. In addition, it provided nurse educators with the opportunity to provide students with realistic learning experiences in a safe environment.

In the present study the practical achievement was evaluated in real clinical area using twenty items observational checklist after two weeks of simulation classes. The difference of achievements scores post simulation in this study either lower or higher than those of the other studies(Ardic,et al 2016 ) (Young and colleagues,2012 ), ( 
Daniel and colleagues,2010 ), (14,15,16 ) It may be explained that the practical achievement was evaluated at various intervals, with different methods, using different tools, with different sample size, and in different topics , and different settings and environment .

Also students' satisfaction with the assigned clinical experience was evaluated in the present study and revealed that students of the simulation group reported a significantly higher satisfaction scores compared to the video group and the control group and then came the vedio group satisfied with the video based training experience,the mean of the total satisfaction of the students in the simulation group was (24.24 \pm 0.69$)$,compared to $(22.21 \pm 3.83)$ and $(17.1 \pm 4.59)$ in the vedio and the control group.

That came in accordance with a study performed in Mansura university,(2015) about (Effectiveness of simulated delivery room classes on practical achievement and satisfaction of maternity nursing students) by ( Marzouk ,2015 ) who concluded that Simulated delivery room classes were an effective trainingapproach; they were equipped the students with practicesthat result in a significantly higher satisfaction scores compared to the conventional training. ${ }^{(6)}$

Also This finding is consistent with prior a study performed by (Ardic et al, 2016 ) in in the United States of America at the College of Nursing at The Ohio State University, (Undergraduate Nursing Students' Perceptions of Obstetric Skills Following High-Fidelity Simulation Experience), who reported that $85.7 \%$ of the students were satisfied with performing application with the simulation model. ${ }^{(14)}$

(Hall and colleagues, 2013 ) who supported the present study finding, in a study about (The effect of simulation based education on baccalaureate nursing students' satisfaction)who reported that the students were very satisfied with the simulation learning activity with a mean score of 24.27 out of 25 possible points. ${ }^{(21)}$

That was also supported in a study about(Confidence in Performing Normal Vaginal Delivery in the Obstetrics Clerkship: A Randomized Trial of Two Simulators ) by (Sabourin, J. N., Van Thournout, R., Jain, V., Demianczuk, N., \& Flood, C. (2014). who concluded that "Simulated NVD training using either an obstetrics mannequin or a birthing pelvis model provides clerkship students wasa positive experience and increased confidence immediately ,It should be implemented early in the rotation positive experience here meaned that they were satisfied with the experience"(22). $^{\text {(22) }}$

Also that agreed with a study of (A systematic review of the effectiveness of simulation-based education on satisfaction and learning outcomes in nurse practitioner programs ) by(Warren, J. N., Luctkar-Flude, M., Godfrey, C., \&Lukewich, J. ,2016) who concluded that" High fidelity simulation increased students' knowledge and confidence, and students were more satisfied with simulation-based teaching in comparison to other methods."(23)

The significantly higher satisfaction level that was reported by the students of the simulation group in the present study may be explained by the fact that students had given a chance for demonstration and making mistakes and re demonstration and correctionof their mistakes that had led to gaining confidence of providing care in real practice setting and subsequently enhance their satisfaction levels.

Asignificantly higher satisfaction with the learning experience and increased self-confidence was observed in the simulation group, and this is an important argument in favor of the use of labor and delivery simulators for undergraduate nursing teaching, as these aspects can have a profound influence on students' motivation.

When students perceive satisfaction with the simulation experience, this realization increase their confidence and their ability to care for actual patients, the present study finding ensures the Chinese proverb "Tell me, I will forget. Show me, I may remember. But involve me and I will learn." Whereas the students of the simulation group bridged the listening and showing phases to performance phase and that increased their satisfaction levels and practical achievement.

\section{Conclusion}

Based on the findings of the present study it was concluded that:

Simulation based training was more effective in improving the nursing students' practical achievement in nursing management of normal vaginal delivery.than video based training ,and the simulation training experience was more satisfying to the nursing students than the video- based training experience.

The conclusions of present study support research hypotheses and aim of the study

\section{Recommendations}

In the light of the present study findings, the following recommendations are suggested:

1. Integrating simulation training into current obstetric curriculums can aid nursing students in developing the clinical performance and skills.

2. Future studies should explore the effectiveness of simulation training in reducing the theory to practice gap, and evaluate knowledge retention, transferability to real patient situations, and impact of simulation on patient outcomes.

3. Future research is also needed to identify whether knowledge and skills acquired from simulation-based training is sufficient or not.

\section{References}

1) Hilderbrand, J. L. (2017).Impact of Simulation on Nursing Students' Self-Efficacyand Knowledge Related to HIV. College of Saint Mary .

2) Wittmann, L. Madhavan, G., \& Al-Khasawneh, E, ( 2015). Perceived benefits of pre-clinical simulationbased training on clinical learning outcomes among Omani undergraduate nursing students. Sultan Qaboos University Medical Journal, 15(1), e105.

3) Birkhead, A. C. S., Callister, L. C., Fletcher, N., Holt, A., \& Curtis, S. (2012). Teaching Physiologic Birth in Maternal-Newborn Courses in Undergraduate Nursing Programs: Current Challenges. The Journal of perinatal education, 213), 169 .

4) Persons, L. D. (2015).Baccalaureate nursing students' perceptions of labor and delivery simulation as a learning method. Colorado State UniversityPueblo. Library

5) World Health Organization, (2018) Reproductive Health Library. WHO recommendation on definitions of the latent and active first stages of labour. 
(February 2018). The WHO Reproductive Health Library; Geneva: World Health Organization.

6) Marzouk, T. (2015). Effectiveness of simulated delivery room classes on practical achievement and satisfaction of maternity nursing students. Journal of Nursing Education and Practice, 5(8), 51.

7) Kelly, M., Lyng, C., McGrath, M., \& Cannon, G. (2016). A multi-method study to determine the effectiveness of, and student attitudes to, online instructional videos for teaching clinical nursing skills. Nurse education today, 29(3), 292-300 .

8) Jang, H. W., \& Kim, K.-J. (2014). Use of onlineclinical videos for clinical skills training for medical students: benefits and challenges. BMC Medical Education, 14(1), 56.

9) Tawalbeh, L. I., \& Tubaishat, A. (2013). Effect of simulation on knowledge of advanced cardiac life support, knowledge retention, and confidence of nursing students in Jordan. Journal of nursing education, 53(1), 38-44.

10) World Health Organization. (2016). Newborns: reducing mortality. Retrieved from http://www.who.int/mediacentre/factsheets/fs333/en/.

11) Mutungi, A., Harvey, S., Kibaru, J., Lugina, H., Kinoti, S., Jennings, L., . . . Hizza, E. (2008). Kenya: assessment of health workforce competency and facility readiness to provide quality maternal health services. USAID, Bethesda: Operation Research Series.

12) Levett-Jones, T., McCoy, M., Lapkin, S., Noble, D., Hoffman, K., Dempsey, J., Roche, J. (2011). The development and psychometric testing of the Satisfaction with Simulation Experience Scale. Nurse education today, 31(7), 705-710.

13) Gudayu, T. W., Badi, M. B., \& Asaye, M. M. (2015). Self-Efficacy, Learner Satisfaction, and Associated Factors of Simulation Based Education among Midwifery Students: A Cross-Sectional Study. Education Research International .

14) Ardic, M., Pinar, G., \& Barker, E. (2016). Undergraduate nursing students' perceptions of obstetric skills following high-fidelity simulation experience. ARC Journal of Gynecology and Obstetrics, 1(2), 19-25.

15) Young K, Eun K, (2012), Sook L. Effects of Simulation-based Education on Communication Skill and Clinical Competence in
Maternity Nursing Practicum Korean Journal of Women Health Nursing. 2012; 18(4): 312320. http://dx.doi.org/10.4069/kjwhn.2012.18.4.312

16) Daniels, K., Arafeh, J., Clark, A., Waller, S., Druzin, M., \& Chueh, J. (2010). Prospective randomized trial of simulation versus didactic teaching for obstetrical emergencies. Simulation in healthcare, 5(1), 40-45.

17) Cooper, S., Cant, R., Porter, J., Bogossian, F., McKenna, L., Brady, S., \& Fox-Young, S. (2012). Simulation based learning in midwifery education: a systematic review. Women and Birth, 25(2), 64-78.

18) Asadollahi Maliheh, Jebraeili Mahnaz, Mohammadpoorasl Asghar,ShamshiriMahmood, and Karimipoor Roghayeh , ( 2016). Comparing the effect of simulation and Video-Based education on mothers' Self-Efficacy in bathing preterm infants. International Journal of Medical Research \& Health Sciences, 5(12), 147-153.

19) Kim, H. Y., Ko, E., \& Lee, E. S. (2012). Effects of simulation-based education on communication skill and clinical competence in maternity nursing practicum. Korean Journal of Women Health Nursing, 18(4), 312-320.

20) Gefferie, S. R., Scholten, A. W., Wijlens, K. A., Bastos, M. L. F., van der Hout-van, M. B., Zwart, H., \& van Meurs, W. J. (2018). An empirical model for educational simulation of cervical dilation in firststage labor. Advances in Simulation, 3(1), 9.

21) Hall, R. M. (2013). Effects of High Fidelity Simulation on Knowledge Acquisition, SelfConfidence, and Satisfaction with Baccalaureate Nursing Students Using the Solomon-Four Research Design.

22) Sabourin, J. N., Van Thournout, R., Jain, V., Demianczuk, N., \& Flood, C. (2014). Confidence in performing normal vaginal delivery in the obstetrics clerkship: a randomized trial of two simulators. Journal of Obstetrics and Gynaecology Canada, 36(7), 620-627.

23) Warren, J. N., Luctkar-Flude, M., Godfrey, C., \& Lukewich, J. (2016). A systematic review of the effectiveness of simulation-based education on satisfaction and learning outcomes in nurse practitioner programs. Nurse Education Today, 46, 99-108 